\title{
Chemical Constitution, Morphological Characteristics, and Biological Properties of ProRoot Mineral Trioxide Aggregate and Ortho Mineral Trioxide Aggregate
}

\author{
Kee Yeon Kum¹, Yeon Jee Yoo ${ }^{1}$, Seok Woo Chang $^{2}$ \\ 'Department of Conservative Dentistry, Dental Research Institute and BK21 Program, Seoul National University \\ Dental Hospital, School of Dentistry, Seoul National University, ${ }^{2}$ Department of Conservative Dentistry, \\ School of Dentistry, Kyung Hee University, Seoul, Korea
}

Purpose: This study sought to compare the elemental constitution, morphological characteristics, particle size distribution, biocompatibility, and mineralization potential of Ortho MTA (OMTA) and ProRoot MTA (PMTA).

Materials and Methods: OMTA and PMTA were compared using energy-dispersive spectrometry, particle size analysis, and scanning electron microscopy. The biocompatibility and mineralization-related gene expression (osteonectin and osteopontin) of both MTAs were also compared using methylthiazol tetrazolium assay and reverse transcription-polymerization chain reaction analysis, respectively. The results were analyzed by Kruskal-Wallis test with Bonferroni correction. P-value of $<0.05$ was considered significant.

Result: The morphology of OMTA powders was similar to that of PMTA. The constituent elements of both MTAs were calcium, silicon, and aluminum. The mean particle sizes of OMTA and PMTA were 4.60 and $3.34 \mathrm{~mm}$, respectively. Both MTAs had equally favorable in vitro biocompatibility and affected the messenger RNA expression of osteonectin and osteopontin.

Conclusion: Within the limitations of this study, OMTA could be a promising biomaterial in clinical endodontics.

Key Words: Biocompatibility; Energy-dispersive spectrometry; Mineralization-related gene expression; Ortho MTA; Particle size analyzer; Scanning electron microscopy

Corresponding Author: Seok Woo Chang

Department of Conservative Dentistry, School of Dentistry, Kyung Hee University, 1 Hoegi-dong, Dongdaemun-gu, Seoul 130-701, Korea

TEL : +82-2-958-9430, FAX : +82-2-960-5108, E-mail : swc2007smc@gmail.com

Received for publication October 7, 2013; Returned after revision November 14, 2013; Accepted for publication November 21, 2013

Copyright $\odot 2013$ by Korean Academy of Dental Science

(c) This is an open access article distributed under the terms of the Creative Commons Attribution Non-Commercial License (http://creativecommons.org/licenses/ by-nc/3.0) which permits unrestricted non-commercial use, distribution, and reproduction in any medium, provided the original work is properly cited. 


\section{Introduction}

Mineral trioxide aggregate (ProRoot MTA; Dentsply Tulsa Dental Specialties, Tulsa, OK, USA) has been used successfully as root-end filling material $^{1,2)}$, perforation repair material ${ }^{3)}$, and pulpcapping material $^{4)}$. The good clinical performance of mineral trioxide aggregate (MTA) is attributed to its good sealing ability ${ }^{5,6)}$, biocompatibility ${ }^{1,7)}$, and capacity to promote mineralized tissue formation ${ }^{8)}$. These properties of MTA stem from its many desirable characteristics, including its elemental constitution $^{9)}$ and particle size distribution ${ }^{10)}$.

The constituent compounds of MTA are important in determining its characteristics since these could affect the setting time, compressive strength, and biological properties of MTA ${ }^{11)}$. The particle size of MTA is also crucial, considering the fact that it could affect the handling properties, surface area, and biological activity of the material ${ }^{10)}$. One previous study reported that the smaller particle size of Portland cement increased the setting reaction rate and improved its early age strength ${ }^{12}$. Investigations evaluating the biocompatibility of MTA and its ability to promote the formation of mineralized tissue are also essential because the material could be in direct contact with pulpal or periradicular tissues.

Many bioactive ceramic types of cement that could be used as alternatives to ProRoot MTA have been developed, and these have been introduced in the dental market worldwide ${ }^{13-15)}$. One such cement, Ortho MTA (BioMTA Ltd., Seoul, Korea), was recently developed in Korea, and it satisfies the International Standardization Organization regulation concerning arsenic and lead contents ${ }^{16)}$. The suggested use of this material is largely the same as that for ProRoot MTA.

Considering the fact that the heavy metal content of Ortho MTA was reported to be lower than that of ProRoot MTA ${ }^{17}$, this material could be considered one possible alternative to ProRoot MTA. Because Ortho MTA is a newly developed material, however, no published studies are available as to its chemical and morphological characteristics, cytotoxicity, or mineralization potential. Therefore, this present study sought to compare the chemical constitution, biocompatibility, particle size distribution, and ability to promote mineralized tissue formation of Ortho MTA and ProRoot MTA.

Table 1. Components of the mineral trioxide aggregate (MTA) materials tested in this study

\begin{tabular}{cl}
\hline Commercial brand of MTA & \multicolumn{1}{c}{ Component } \\
\hline ProRoot MTA (tooth colored formula) & Tricalcium silicate $(\mathrm{CaO})_{3} \cdot \mathrm{SiO}_{2}$ \\
& Dicalcium silicate $(\mathrm{CaO})_{2} \cdot \mathrm{SiO}_{2}$ \\
& Tricalcium aluminate $(\mathrm{CaO})_{3} \cdot \mathrm{Al}_{2} \mathrm{O}_{3}$ \\
& Tetracalcium aluminoferrite $(\mathrm{CaO})_{4} \cdot \mathrm{Al}_{2} \mathrm{O}_{3} \cdot \mathrm{Fe}_{2} \mathrm{O}_{3}$ \\
& Gypsum, $\mathrm{CaSO}_{4} \cdot 2 \mathrm{H}_{2} \mathrm{O}$ \\
Ortho MTA & Free calcium oxide, $\mathrm{CaO}$ \\
& Bismuth oxide, $\mathrm{Bi}_{2} \mathrm{O}_{3}$ \\
& Tricalcium silicate $(\mathrm{CaO})_{3} \cdot \mathrm{SiO}_{2}$ \\
& Dicalcium silicate $(\mathrm{CaO})_{2} \cdot \mathrm{SiO}_{2}$ \\
& Tricalcium aluminate $(\mathrm{CaO})_{3} \cdot \mathrm{Al}_{2} \mathrm{O}_{3}$ \\
& Tetracalcium aluminoferrite $\left(\mathrm{CaO}_{4} \cdot \mathrm{Al}_{2} \mathrm{O}_{3} \bullet \mathrm{Fe}_{2} \mathrm{O}_{3}\right.$ \\
& Free calcium oxide, $\mathrm{CaO}$ \\
\hline
\end{tabular}

The ProRoot MTA was from Dentsply Tulsa Dental Specialties, and the Ortho MTA was from BioMTA. 


\section{Materials and Methods}

In this study, Ortho MTA (Lot \#O 1005 T 30 A 1, BioMTA) and ProRoot MTA (Lot \#10003598A, Dentsply Tulsa Dental Specialties) were used. The main components of ProRoot MTA are tricalcium silicate, dicalcium silicate, tricalcium aluminate, tetracalcium aluminoferrite, gypsum, and bismuth oxide. The main components of Ortho MTA are tricalcium silicate and dicalcium silicate. Note, however, that Ortho MTA is free of gypsum. The components of ProRoot MTA and Ortho MTA are shown in Table 1.

\section{Morphological and Chemical Composition} Analyses

The morphological examination of Ortho MTA powder compared with ProRoot MTA powder was carried out using scanning electron microscope (SEM, Model X5000 S4700; Hitachi, Schaumburg, IL, USA; x500), and elemental analysis was performed with an energy-dispersive spectrometer (EDS) attached to SEM. A thin layer of each powder was dispersed over a polymethyl methacrylate slab mounted on an aluminum stub. Each specimen was coated with carbon (K250; Emitech, Ashford, UK) for electrical conductivity.

\section{Particle Size Analysis}

Particle size analysis of Ortho MTA and ProRoot MTA was also done. Each sample was dispersed in distilled water. The particle-to-dispersant ratio was $0.0023 \%$ by volume, and a light-scattering method was used to detect the particle size of the two samples. A Mastersizer 2,000 particle size analyzer
(Malvern Instruments Ltd., Worcestershire, UK) was used for this analysis. The mean particle size and the particle size distribution of each sample were investigated using this method.

\section{Cell Culture and Cytotoxicity Test Using Me-} thylthiazol Tetrazolium Assay

MG-63 (CRL-1427) human osteosarcoma cells obtained from the American Type Culture Collection (ATCC, Manassas, VA, USA) were cultured in Dulbecco's modified Eagle's medium supplemented with $10 \%$ (vol/vol) fetal bovine serum (Gibco, Grand Island, NY, USA) and $1 \%$ (wt/vol) antibiotics/antimycotics (100 U of penicillin, $100 \mu \mathrm{g}$ of streptomycin, and $0.25 \mu \mathrm{g}$ of amphotericin B; Gibco) at $37^{\circ} \mathrm{C}$ in a humidified $5 \%$ (vol/vol) $\mathrm{CO}_{2}$ atmosphere. One gram of ProRoot MTA or Ortho MTA was mixed according to the manufacturer's instructions. After mixing, the materials were placed in sterilized molding rings with inner diameter of $5 \mathrm{~mm}$ and thickness of $1 \mathrm{~mm}$. Any excess material was removed using sterile blades, and the materials were left to set for 3 hours at room temperature in $97 \%$ humidity. One milliliter of medium containing $5 \times 10^{4}$ MG-63 cells was seeded into each well of the 24 -well plates. The cells were cultured with a culture plate insert with MTA specimen on the top surface of the culture plate insert. Intermediate restorative material (IRM, Dentsply Tulsa Dental Specialties) and empty tubes were used as positive and negative controls. After 1,3, and 7 days of incubation, cell viability was assessed using an methylthiazol tetrazolium (MTT) (3-[4,5-dimethylthiazol-2yl]-2,5-diphenyl2H-tetrazolium bromide) assay kit. The cells were

Table 2. Reverse transcriptase-polymerase chain reaction primers sequence

\begin{tabular}{clc}
\hline Gene & \multicolumn{1}{c}{ Sequence $\left(5^{\prime}-3^{\prime}\right)$} & Size $(\mathrm{bp})$ \\
\hline Osteonectin & Forward: AGA AGC TGC GGG TGA AGA A & 405 \\
& Reverse: TGC CAG TGT ACA GGG AAG ATG & 347 \\
Osteopontin & Forward: CCA AGT AAG TCC AAC GAA AG & \\
& Reverse: GGT GAT GTC CTC GTC TGT A & \\
\hline
\end{tabular}


incubated with $5.7 \mathrm{~mol} / \mathrm{L}$ of MTT solution for 4 hours in a tissue culture incubator. Afterward, 200 $\mu \mathrm{l}$ dimethyl sulfoxide solution was added to the cell culture wells, with the plates shaken for 10 minutes at room temperature to dissolve the precipitated formazan crystals. The solution was centrifuged for 10 minutes, and the optical density of the supernatant was measured at $540 \mathrm{~nm}$ using an enzyme-linked immunosorbent assay plate reader (PowerWave; BioTek Instruments, Winooski, VT, USA).

\section{RNA Isolation and Reverse Transcription-} polymerase Chain Reaction

After 1, 3, and 7 days of culture, the total RNA of the incubated cells was extracted using Trizol

\section{A}

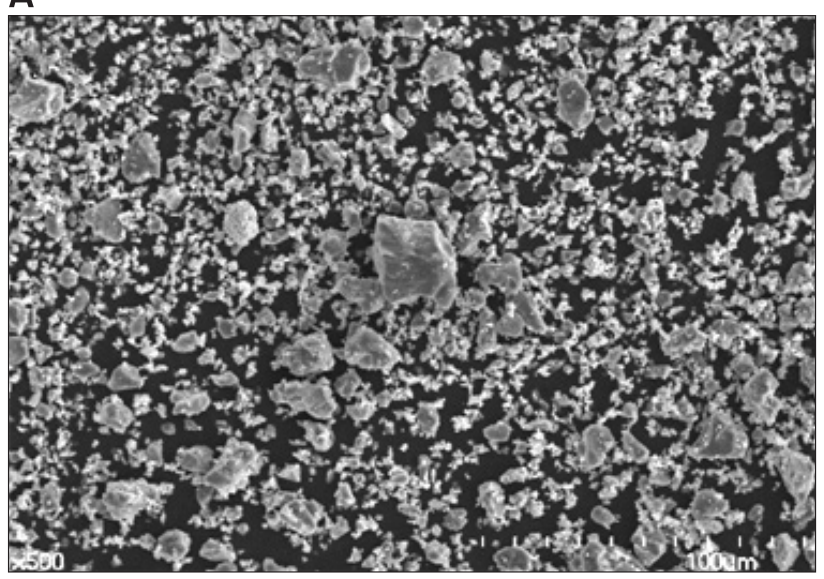

B

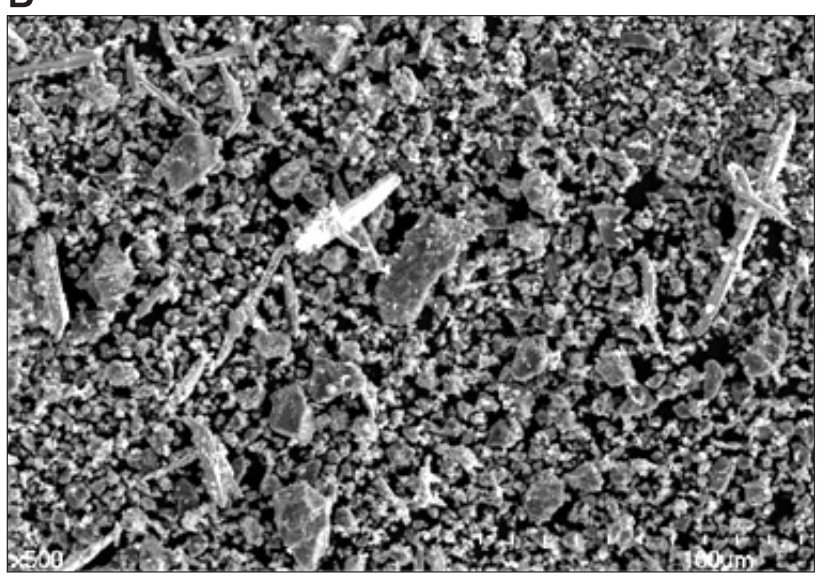

D

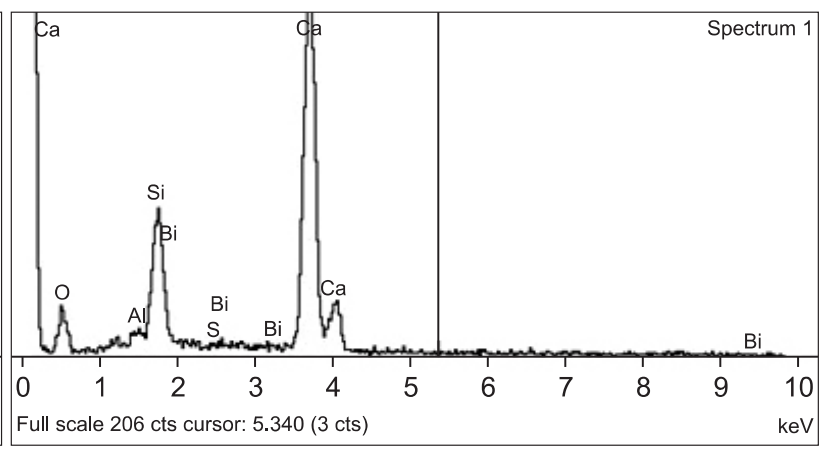

E

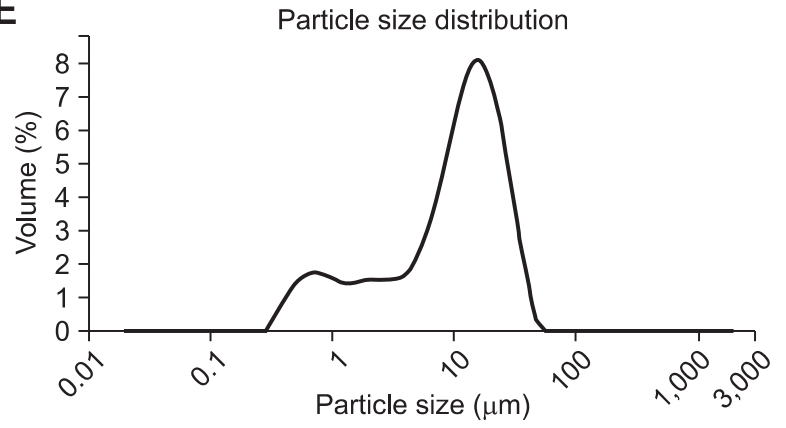

$\mathbf{F}$

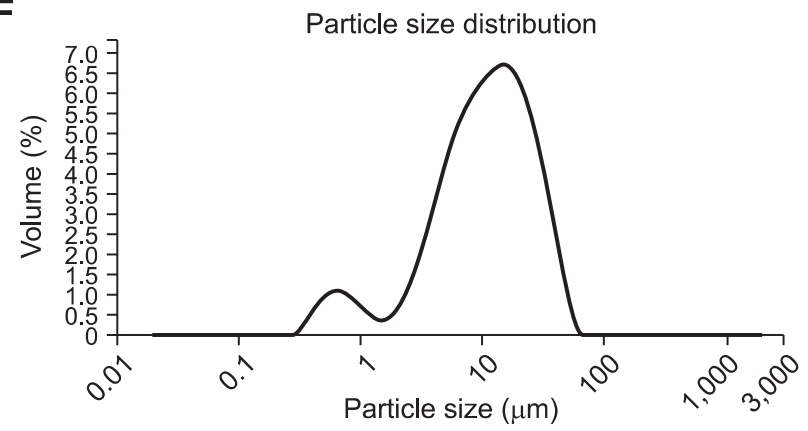

Fig. 1. Morphological appearance of ProRoot MTA (A) and Ortho MTA (B) by scanning electron microscopy $(x 5,000)$. The energydispersive spectrometry analysis showed similar compositional elements in the ProRoot (C) and Ortho (D) MTAs. The particle size distributions of ProRoot MTA (E) and Ortho MTA (F) showed little difference. MTA: mineral trioxide aggregate. 
reagent (Life Technologies, Gaithersburg, MD, USA) according to the manufacturer's recommendations. Reverse transcription (RT) of RNA was performed using an AccuPower RT Premix (Bioneer, Daejeon, Korea), which was also utilized for amplifying the RT-generated DNA. Primer sequences and their major functions for osteonectin (ON) and osteopontin (OPN) are detailed in Table 2. The polymerase chain reaction (PCR) products were resolved on a $1.5 \%$ agarose gel and stained with ethidium bromide. A gel image was recorded and analyzed using Gel Doc (Bio-Rad, Hercules, CA, USA) and were normalized to the housekeeping gene, glyceraldehyde 3-phosphate dehydrogenase, as a template.

\section{Statistical Analysis}

Statistical analyses of the MTT assay and RT-PCR data were carried out using the Kruskal-Wallis test with Bonferroni correction (SPSS Statistics version 17.0; SPSS Inc., Chicago, IL, USA). The confidence interval was $95 \%$, and a $P$-value of $<0.05$ was considered significant.

\section{Result}

1. Scanning Electron Microscope and Energydispersive Spectrometer Analyses

The SEM examination revealed that both ProRoot MTA and Ortho MTA have relatively homogeneous powder, and that both contain some larger particles (Fig. 1A, 1B). The EDS analysis showed that both MTAs were composed mainly of elements such as calcium, silicon, and aluminum (Fig. 1C, 1D).

\section{Particle Size Analysis}

The mean particle size of ProRoot MTA was $3.34 \mu \mathrm{m}$, whereas that of Ortho MTA was 4.60

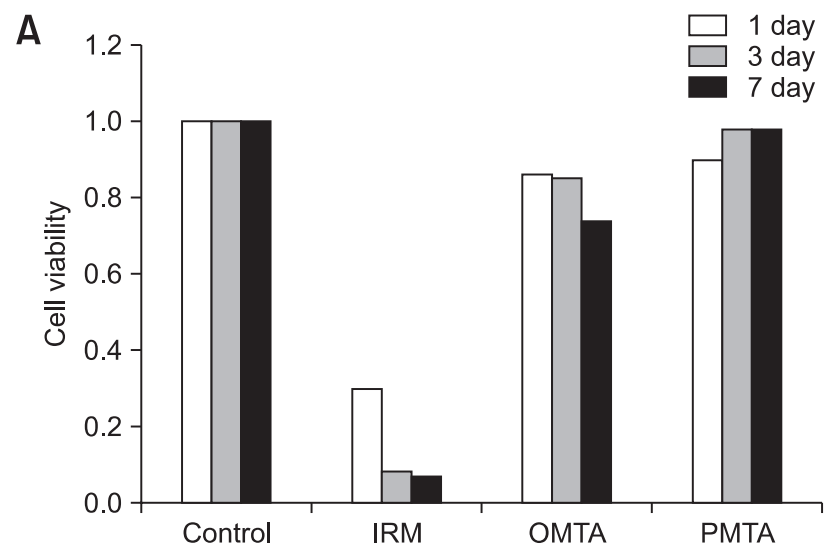

B


Fig. 2. Results of the methylthiazol tetrazolium assay and reverse transcription-polymerase chain reaction analysis (A). Cell viability was assessed after incubating MG-63 cells for 1, 3, and 7 days with intermediate restorative material (IRM), ProRoot MTA (PMTA) or Ortho MTA (OMTA). (B) The messenger RNA expression of osteonectin (ON), osteopontin (OPN), and glyceraldehyde 3-phosphate dehydrogenase (GAPDH) was assessed after incubating MG-63 cells with IRM, PMTA or OMTA for 1, 3, and 7 days (x200). MTA: mineral trioxide aggregate. 
$\mu \mathrm{m}$. Mastersizer graphs revealed that the particle sizes of both MTA cements were in the range of approximately $0.3 \sim 50 \mu \mathrm{m}$ (Fig. 1E, 1F).

\section{Cytotoxicity Test Using MTT Assay}

Both MTAs showed statistically higher cell viability values than IRM at all incubation times (Fig. 2A). Compared with the control, the percentage of viable cells was $90 \%$ for ProRoot MTA and $86 \%$ for Ortho MTA after 1 day of incubation. After 3 days of incubation, the percentage of viable cells was 98\% for ProRoot MTA and 85\% for Ortho MTA; after 7 days of incubation, cell viability was $98 \%$ for ProRoot MTA and 74\% for Ortho MTA (Fig. 2A). ProRoot MTA and Ortho MTA showed no statistically significant difference in cell viability at any incubation time $(\mathrm{P}>0.05)$.

\section{RNA Isolation and Reverse Transcription- Polymerase Chain Reaction}

After 1 day of incubation, the messenger RNA (mRNA) expression of $\mathrm{ON}$ significantly increased in both MTA groups $(\mathrm{P}<0.05)$, whereas the mRNA expression of OPN were decreased in both MTAs $(\mathrm{P}<0.05)$ compared with the control groups. After 3 days of incubation, the mRNA expression of OPN increased in Ortho MTA compared with those in the control and IRM groups $(\mathrm{P}<0.05)$. After 7 days of incubation, the mRNA expression of OPN increased for ProRoot MTA compared with that of the control groups $(\mathrm{P}<0.05)$. However, no significant differences in the mRNA expression of $\mathrm{ON}$ were observed between the groups ( $\mathrm{P}>0.05)$.

\section{Discussion}

This study compared the chemical constitution, particle size, biocompatibility, and mineralization potential of Ortho MTA and ProRoot MTA. With regard to the morphological characteristics of the two MTAs, particles in the ProRoot MTA appeared relatively homogeneous, with some large particles. These results are consistent with the findings of previous studies ${ }^{9,18)}$. The morphological characteristics of Ortho MTA were similar to those of ProRoot MTA.

The particle size of Portland cement is known to affect its handling characteristics ${ }^{19)}$. To our knowledge, however, the only study that investigated the particle size of ProRoot MTA is that by Komabayashi and Spångberg ${ }^{10)}$. The authors reported that the mean particle size of ProRoot MTA was $2.96 \mu \mathrm{m}$. The mean particle size of ProRoot MTA in our study was $3.34 \mu \mathrm{m}$, which was in the same range as that of Komabayashi and Spångberg ${ }^{10)}$. Additionally, we found that the mean particle size of Ortho MTA $(4.60 \mu \mathrm{m})$ was larger than that of ProRoot MTA. The effect of such size difference on the physical properties of Ortho MTA needs to be determined in future studies.

Several studies have investigated the chemical composition of ProRoot MTA ${ }^{20-22)}$. The main elements of ProRoot MTA have been reported to be calcium, silicon, and aluminum ${ }^{9,23)}$, and this was confirmed in the present study. The main elements detected in the Ortho MTA were almost similar to those of ProRoot MTA. Note, however, that the previous study of Chang et al. ${ }^{16)}$ revealed that ProRoot MTA contained a little amount of arsenic (1.16 ppm), whereas Ortho MTA was free of arsenic. Furthermore, they reported that Ortho MTA contained significantly lower levels of heavy metals (cadmium, chromium, copper, iron, manganese, and nickel) than ProRoot MTA ${ }^{17}$. The effect of these differences in heavy metal content on the biochemical properties of MTA need further investigation.

Previous studies have shown that ProRoot MTA is biocompatible with and nontoxic to pulpal and periradicular tissues ${ }^{9,24,25)}$. The present study showed that the cytotoxicity of both MTAs was significantly less than that of IRM and found no significant difference between the two MTAs. These results suggest that the biocompatibility of Ortho MTA is 
comparable with that of ProRoot MTA. Most of the previous studies have evaluated the cytotoxicity of MTA for a relatively short duration ${ }^{9,25)}$. Considering the fact that ProRoot MTA maintains high $\mathrm{pH}$ and high calcium ion release for up to 7 days $^{26)}$, an evaluation of the cellular response to MTA for 1 week may be more clinically relevant. In addition, in the present study, the MTA samples themselves were cultured with the MG-63 cells ${ }^{25,27}$, whereas other studies have used MTA eluates ${ }^{28,29}$. Using the samples of MTA themselves instead of MTA eluates more closely simulates the clinical situations wherein pulpal or periradicular tissues are in direct contact with MTA.

Among the various genes known to be related to the formation of mineralized tissue, we investigated the mRNA expression of ON and OPN because the two have been reported to be involved in bone initiation, mineralization, and remodeling ${ }^{30,31)}$. The present study showed that ProRoot MTA increased the mRNA expression of ON after 1 day of incubation and that of OPN after 7 days of incubation compared to the control group. Generally, there was no significant difference in the mRNA expression of ON and OPN between the two MTAs. Reichert et al. ${ }^{30)}$ reported that $\mathrm{ON}$, a major non-collagenous matrix protein in bone and dentin, plays a role in the initiation of mineralization. On the other hand, Zhang et al. ${ }^{31)}$ stated that OPN takes part in the formation of mineralized tissue. The present results suggest that both MTA cements have the potential to promote mineralization.

\section{Conclusion}

The two MTA cements have similar chemical compositions and morphological characteristics. The particle size of ProRoot MTA was slightly smaller than that of Ortho MTA. Both MTA showed good biocompatibility and upregulation of mineralization-related gene expression.
Considering the previous report on Ortho MTA having lower heavy metal content than ProRoot MTA $^{17}$, these results suggest that Ortho MTA could be a useful endodontic biomaterial. Note, however, that this was an in vitro study, and further in vivo investigation of the tissue compatibility of Ortho MTA and its dentin/cementum-formation potential is necessary to evaluate the usefulness of Ortho MTA as a possible alternative to ProRoot MTA.

\section{Acknowledgement}

This research was supported by the Basic Science Research Program through the Ministry of Education, Science, and Technology (MEST)-funded National Research Foundation of Korea (NRF) (Dr. Chang SW, 2011-0014231) and MEST-funded NRF of Korea (Dr. Kum KY, 2009-0086835). This study was supported by a grant from Kyung Hee University in 2013 (KHU-20131045).

\section{References}

1. Bodrumlu E. Biocompatibility of retrograde root filling materials: a review. Aust Endod J. 2008; 34: 30-5.

2. Asgary S, Eghbal MJ, Parirokh M, Ghoddusi J. Effect of two storage solutions on surface topography of two root-end fillings. Aust Endod J. 2009; 35: 147-52.

3. Ford TR, Torabinejad M, McKendry DJ, Hong CU, Kariyawasam SP. Use of mineral trioxide aggregate for repair of furcal perforations. Oral Surg Oral Med Oral Pathol Oral Radiol Endod. 1995; 79: 75663.

4. Reston EG, de Souza Costa CA. Scanning electron microscopy evaluation of the hard tissue barrier after pulp capping with calcium hydroxide, mineral trioxide aggregate (MTA) or ProRoot MTA. Aust Endod J. 2009; 35: 78-84.

5. Lee SJ, Monsef M, Torabinejad M. Sealing ability of a mineral trioxide aggregate for repair of lateral 
root perforations. J Endod. 1993; 19: 541-4.

6. Bidar M, Moradi S, Jafarzadeh H, Bidad S. Comparative SEM study of the marginal adaptation of white and grey MTA and Portland cement. Aust Endod J. 2007; 33: 2-6.

7. Torabinejad M, Ford TR, Abedi HR, Kariyawasam SP, Tang HM. Tissue reaction to implanted rootend filling materials in the tibia and mandible of guinea pigs. J Endod. 1998; 24: 468-71.

8. Yuan Z, Peng B, Jiang H, Bian Z, Yan P. Effect of bioaggregate on mineral-associated gene expression in osteoblast cells. J Endod. 2010; 36: 1145-8.

9. Hwang YC, Lee SH, Hwang IN, Kang IC, Kim MS, Kim SH, Son HH, Oh WM. Chemical composition, radiopacity, and biocompatibility of Portland cement with bismuth oxide. Oral Surg Oral Med Oral Pathol Oral Radiol Endod. 2009; 107: e96-102.

10. Komabayashi T, Spångberg LS. Comparative analysis of the particle size and shape of commercially available mineral trioxide aggregates and Portland cement: a study with a flow particle image analyzer. J Endod. 2008; 34: 94-8.

11. Saidon J, He J, Zhu Q, Safavi K, Spångberg LS. Cell and tissue reactions to mineral trioxide aggregate and Portland cement. Oral Surg Oral Med Oral Pathol Oral Radiol Endod. 2003; 95: 483-9.

12. Camilleri J, Montesin FE, Di Silvio L, Pitt Ford TR. The chemical constitution and biocompatibility of accelerated Portland cement for endodontic use. Int Endod J. 2005; 38: 834-42.

13. Park JW, Hong SH, Kim JH, Lee SJ, Shin SJ. X-Ray diffraction analysis of white ProRoot MTA and Diadent BioAggregate. Oral Surg Oral Med Oral Pathol Oral Radiol Endod. 2010; 109: 155-8.

14. Oliveira IR, Pandolfelli VC, Jacobovitz M. Chemical, physical and mechanical properties of a novel calcium aluminate endodontic cement. Int Endod J. 2010; 43: 1069-76.

15. Mukhtar-Fayyad D. Cytocompatibility of new bioceramic-based materials on human fibroblast cells (MRC-5). Oral Surg Oral Med Oral Pathol
Oral Radiol Endod. 2011; 112: e137-42.

16. Chang SW, Baek SH, Yang HC, Seo DG, Hong ST, Han SH, Lee Y, Gu Y, Kwon HB, Lee W, Bae KS, Kum KY. Heavy metal analysis of Ortho MTA and ProRoot MTA. J Endod. 2011; 37: 1673-6.

17. Kum KY, Zhu Q, Safavi K, Gu Y, Bae KS, Chang SW. Analysis of six heavy metals in Ortho mineral trioxide aggregate and ProRoot mineral trioxide aggregate by inductively coupled plasma-optical emission spectrometry. Aust Endod J. 2013; 39: 126-30.

18. Dammaschke T, Gerth HU, Züchner H, Schäfer E. Chemical and physical surface and bulk material characterization of white ProRoot MTA and two Portland cements. Dent Mater. 2005; 21: 731-8.

19. Bentz DP, Garboczi EJ, Haecker CJ, Jensen OM. Effects of cement particle size distribution on performance properties of Portland cement-based materials. Cem Concr Res. 1999; 29: 1663-71.

20. Belío-Reyes IA, Bucio L, Cruz-Chavez E. Phase composition of ProRoot mineral trioxide aggregate by X-ray powder diffraction. J Endod. 2009; 35: 875-8.

21. Comin-Chiaramonti L, Cavalleri G, Sbaizero O, Comin-Chiaramonti P. Crystallochemical comparison between Portland cements and mineral trioxide aggregate (MTA). J Appl Biomater Biomech. 2009; 7: 171-8.

22. Camilleri J. The chemical composition of mineral trioxide aggregate. J Conserv Dent. 2008; 11: 141-3.

23. Hwang YC, Kim DH, Hwang IN, Song SJ, Park YJ, Koh JT, Son HH, Oh WM. Chemical constitution, physical properties, and biocompatibility of experimentally manufactured Portland cement. J Endod. 2011; 37: 58-62.

24. Vajrabhaya LO, Korsuwannawong S, Jantarat J, Korre S. Biocompatibility of furcal perforation repair material using cell culture technique: Ketac Molar versus ProRoot MTA. Oral Surg Oral Med Oral Pathol Oral Radiol Endod. 2006; 102: e48-50.

25. Jafarnia B, Jiang J, He J, Wang YH, Safavi KE, Zhu Q. Evaluation of cytotoxicity of MTA employing 
various additives. Oral Surg Oral Med Oral Pathol Oral Radiol Endod. 2009; 107: 739-44.

26. Vivan RR, Zapata RO, Zeferino MA, Bramante CM, Bernardineli N, Garcia RB, Hungaro Duarte MA, Tanomaru Filho M, Gomes de Moraes I. Evaluation of the physical and chemical properties of two commercial and three experimental rootend filling materials. Oral Surg Oral Med Oral Pathol Oral Radiol Endod. 2010; 110: 250-6.

27. Kim EC, Lee BC, Chang HS, Lee W, Hong CU, Min KS. Evaluation of the radiopacity and cytotoxicity of Portland cements containing bismuth oxide. Oral Surg Oral Med Oral Pathol Oral Radiol Endod. 2008; 105: e54-7.

28. Damas BA, Wheater MA, Bringas JS, Hoen MM.
Cytotoxicity comparison of mineral trioxide aggregates and EndoSequence bioceramic root repair materials. J Endod. 2011; 37: 372-5.

29. Alanezi AZ, Jiang J, Safavi KE, Spangberg LS, Zhu Q. Cytotoxicity evaluation of endosequence root repair material. Oral Surg Oral Med Oral Pathol Oral Radiol Endod. 2010; 109: e122-5.

30. Reichert T, Störkel S, Becker K, Fisher LW. The role of osteonectin in human tooth development: an immunohistological study. Calcif Tissue Int. 1992; 50: 468-72.

31. Zhang W, Li Z, Peng B. Effects of iRoot SP on mineralization-related genes expression in MG63 cells. J Endod. 2010; 36: 1978-82. 